\title{
Research characteristics and status on Environmental Psychology: a bibliometric and knowledge mapping analysis
}

\author{
Jun Hua $\mathrm{XU}^{1}$, Lei Ye ZHU ${ }^{1, *}$, and Hai Bin $\mathrm{WANG}^{2,1, *}$ \\ ${ }^{1}$ School of Educational Science, Huangshan University, Huangshan, 245041, China \\ ${ }^{2}$ School of Business Administration, Zhejiang Gongshang University, Hangzhou 310018, China
}

\begin{abstract}
Environmental psychology is an interdisciplinary field that focuses on the interplay between individuals and their built and natural environments. Great progress has been made in the areas of environmental psychology by researchers form many countries. However, a thorough quantitative analysis to the emergent research trends and topics has not been found. To reveal the research characteristics and status on Environmental Psychology, 853 related papers from Web of Science core collection were analysed by CiteSpace II. The results show that: (1) the domain of Environmental Psychology was started in 1960s and showed a low growth over the past half century, which reaches a historical peak in 2017. Gifford, USA and the Journal of Environmental Psychology top the list of contributing authors, country and publication respectively. (2) "Environmental Psychology" is the most frequently keywords and has the longest span of the bursts. "ambient scent", "recycling", "children as outsiders" and "ambient temperature" are the top four largest clusters, which are the popular research topics in the domain of environmental psychology.
\end{abstract}

\section{Introduction}

Environmental psychology is an interdisciplinary field that focuses on the interplay between individuals and their built and natural environments [1]. The environments were broad, encompassing natural environments, social settings, built environments, learning environments, informational environments, and so on. Especially as people spend more time on network, the virtual environments are coming under increasing research attention ${ }^{[1]}$. The discipline is considered to be a key component of human, animal, and environmental welfare and is essential for policy-making [1]. It was in 1967 that "environmental psychology" was mentioned in the article, which was published by Rohles [2], but the birth of the discipline was marked by the establishment of "Journal of Environmental Psychology", which was created by Canter in 1979[3]. Subsequently, environmental psychology attracts many researchers' attention, and the domain includes theory research and practice aiming at improving human relations with the natural environment and making the built environment more humane [4]. In the theoretical analysis of the field, researchers have explored the core concepts [5], such as place identity, place attachment, environmental consciousness, behavior settings and so on. For instance, the ontology, epistemology and methodology proposed by Brown lay an important foundation for the research of pro-environmental psychology [6]. In the practical analysis of the field, researchers have explored the impact on the built environments to improve the environments, such as the design of nursing home [7], school environments [8], military camp [9], modern interior [10], architecture [11], and even the design of mobile application stores form the environmental psychology perspective [12]. As mention in the literature review, great progress has been made in the areas of environmental psychology from 1967 to 2017, however, very little was found in the literature to review the fruitful achievements in the field through a quantitative analysis by bibliometric and Knowledge Mapping. The purpose of the current study was to determine a quantitative review of Environmental Psychology researches based on the bibliometric analysis and knowledge mapping with the help of the CiteSpace II, which can explore the hot spot transformation in the research evolution of Environmental Psychology and then further promote the development the field of environmental psychology.

\section{Methodology}

\section{1 data sources}

The sources and cited papers for analysis were from the Web of Science core collection, which is the largest and most comprehensive academic information resources in the world covering over 8,700 core academic journals with the most influential research fields, for instance, science, engineering, biomedicine and other fields. The search conducted in the Web of Science core collection yielded 853 papers of all types under the WoS topic of

\footnotetext{
* Corresponding author: zhuleiye@hsu.edu.cn or wanghaibin@hsu.edu.cn
} 
“environmental psychology", which contains 556 articles, 127 proceedings paper, 75 book reviews, 57 reviews, 24 meeting abstracts, and so on.

\section{2 data processing}

853 papers were saved in RIS format which includes the crucial information, encompassing title, authors, affiliations, publication name, abstract, keywords and so on. The bibliometric and knowledge mapping analyses were conducted with Java CiteSpace II software [13], which can used to bibliometric analysis and knowledge mapping analysis [14].

\section{Results}

\subsection{Bibliometric analysis results}

\subsubsection{Chronology statistics}

Based on the yearly analysis, the annual number of environmental psychology study published from 1967 to 2017 is shown in Fig. 1. The domain of Environmental Psychology was started in 1960s and showed a low growth over the past half century. Until 2002, the publishing trend of the field demonstrated a year-on-year growth, and reached a historical peak in 2017.

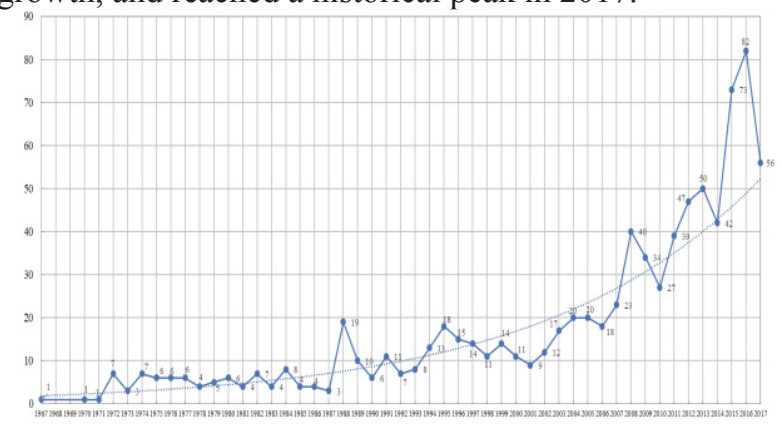

Fig.1. The annual number of the research (1967-2017)

\subsubsection{Author statistics}

Table 1 outlines the top 10 contributing authors and the numbers of their published papers. As shown, all of them have published more than five articles and Gifford tops the list with a total of ten articles, followed by Garling and Rioux, each of which has more than seven articles.

Table 1. Top 10 contributing authors

\begin{tabular}{|c|c|c|}
\hline Rank & Author & FREQ \\
\hline 1 & Gifford R & 10 \\
\hline 2 & Garling T & 8 \\
\hline 3 & Rioux L & 8 \\
\hline 4 & Spencer C & 7 \\
\hline 5 & Joye Y & 6 \\
\hline 6 & Pol E & 6 \\
\hline 7 & Stokols D & 6 \\
\hline 8 & Wapner S & 6 \\
\hline 9 & Anonymous & 5 \\
\hline 10 & Bonaiuto M & 5 \\
\hline
\end{tabular}

\subsubsection{Country statistics}

Table 2 depicts the top 10 countries contributing to the studies on Environmental Psychology. As seen, USA is the best performer, followed by England, Canada and Australia, and each country has been contributed to more than fifty articles.

Table 2. Top 10 contributing countries

\begin{tabular}{|c|c|c|}
\hline Rank & Country & FREQ \\
\hline 1 & USA & 240 \\
\hline 2 & England & 89 \\
\hline 3 & Canada & 52 \\
\hline 4 & Australia & 50 \\
\hline 5 & Germany & 47 \\
\hline 6 & Netherlands & 37 \\
\hline 7 & Peoples R China & 37 \\
\hline 8 & Sweden & 34 \\
\hline 9 & France & 33 \\
\hline 10 & Italy & 30 \\
\hline
\end{tabular}

\subsubsection{Source publication statistics}

Table 3 depicts the top 10 source publications contributing to the studies on Environmental Psychology. As shown, Journal of Environmental Psychology tops the list with a total of ninety articles, followed by Environment and Behavior, which has been published thirty-six articles.

Table 3. Top 10 contributing source publication

\begin{tabular}{|c|c|c|}
\hline Rank & source publication & FREQ \\
\hline 1 & Journal of Environmental & 90 \\
\hline 2 & Environment and Behavior & 36 \\
\hline 3 & Contemporary Psychology & 16 \\
\hline 4 & International Journal of Psychology & 16 \\
\hline 5 & American Psychologist & 12 \\
\hline 6 & Journal of Business Research & 12 \\
\hline 7 & Annual Review of Psychology & 10 \\
\hline 8 & Revista Latinoamericana De & 10 \\
\hline 9 & Frontiers in Psychology & 9 \\
\hline 10 & Landscape and Urban Planning & 9 \\
\hline
\end{tabular}

\subsection{Knowledge mapping results}

\subsubsection{High frequency keywords}

Table 4 describes the top 10 high frequency keywords in the domain of the Environmental Psychology, as well as their frequencies. As shown, "environmental psychology" is the most frequently keywords. And "behavior", "environment", "perception" and "model" are positioned in the $2^{\text {ed }}, 3^{\text {rd }} 4^{\text {th }}$ and $5^{\text {th }}$ places on the list. Fig 2 visualizes the same result (The higher the frequency, the larger the circle). It indicates that the interplay between individuals and environments attracts researchers' attention continuously in the field of environmental psychology. 
Table 4. Top 10 keywords

\begin{tabular}{|c|c|c|}
\hline Rank & Keywords & FREQ \\
\hline 1 & environmental psychology & 236 \\
\hline 2 & behavior & 94 \\
\hline 3 & environment & 68 \\
\hline 4 & perception & 55 \\
\hline 5 & model & 51 \\
\hline 6 & identity & 44 \\
\hline 7 & health & 44 \\
\hline 8 & psychology & 37 \\
\hline 9 & experience & 36 \\
\hline 10 & community & 35 \\
\hline
\end{tabular}

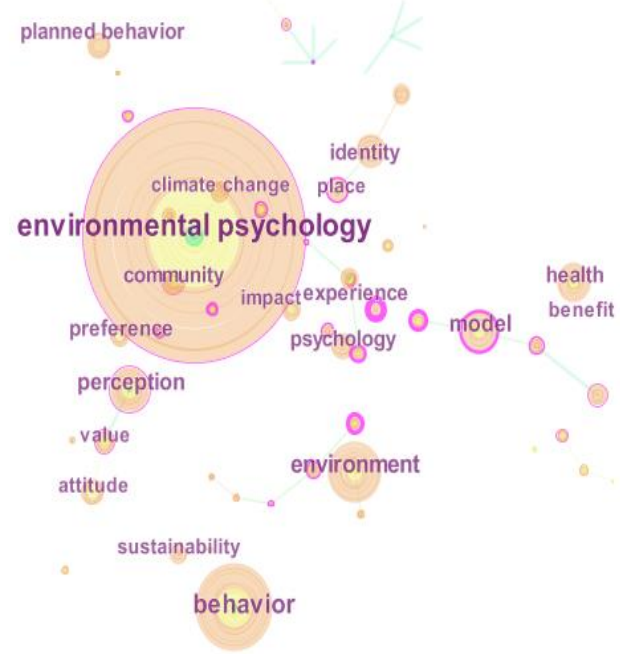

Fig.2. Top 10 keywords

\subsubsection{Popular research trends}

Fig 3 shows the top five keywords with the strongest citation bursts. As indicated, we discover that "environmental psychology" and "behavior" have the longest span, each of which has more than thirty-six years, which indicates that the relationship between environment and behavior is the eternal topic in the domain. In addition, the topic of "climate change" is one of the typical recent research frontiers, which started since 2014 and continued until 2017.

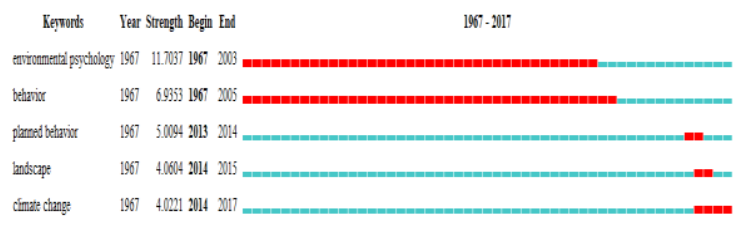

Fig.3. Top five keywords with bursts

\subsubsection{Popular research topics}

Fig 4 shows the top four largest clusters, which were "ambient scent", "recycling", "children as outsiders" and "ambient temperature". As shown, the largest cluster is "ambient scent" (\#0), which contains 30 articles and its Silhouette value is 0.715 . The high-frequency keywords of this cluster contain "environmental psychology", "model", "satisfaction" and "impact". The second largest cluster is "recycling" (\#1), which contains 23 articles and its Silhouette value is 0.846 . The high-frequency keywords of this cluster contain "sustainability". The third largest cluster is "children as outsiders" (\#2), which contains 19 articles and its Silhouette value is 0.900 . The high-frequency keywords of this cluster contain "impact", "attitude", "value" and "experience". The last largest cluster is "ambient temperature" (\#3), which contains 18 articles and its Silhouette value is 0.995. The high-frequency keywords of this cluster contain "perception", "preference", "benefit" and "health".

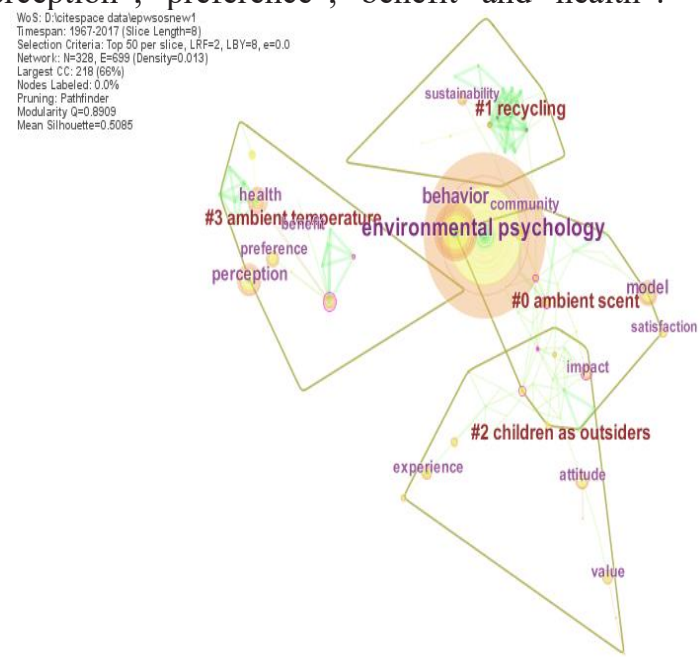

Fig.4. Clusters of the current researchers

\section{Conclusions and further research}

During the past half century, great progress has been made in the areas of environmental psychology by researchers form many countries, such as USA, England, Canada, Australia, Germany, Netherlands, China, and etcetera. However, a thorough quantitative analysis to the emergent research trends and topics has not been found. To fill this gap, the present study was to determine a quantitative review of Environmental Psychology researches based on the bibliometric analysis and knowledge mapping with the help of the CiteSpace II, which can explore the hot spot transformation in the research evolution of the field. In the bibliometric analysis section, the results show that the domain of Environmental Psychology was started in 1960s and showed a low growth over the past half century, 2017 reached a historical peak. Gifford tops the list with a total of ten articles, followed by Garling and Rioux. Similarly, USA is the best performer, followed by England, Canada and Australia. Moreover, the Journal of Environmental Psychology tops the list of the contributing source publications, echoing with the birth of environmental psychology.

In the section of Knowledge mapping analysis, the high frequency keywords are obtained by CiteSpace II. As shown in table 4 and fig 2, "environmental psychology" "behavior", "environment", "perception" and "model" are the most frequently keywords, indicating that the interplay between individuals and environments attracts researchers' attention continuously. Most importantly, the major popular research trends and topics in the field are obtained through keywords 
bursting and clustering by CiteSpace II. As shown, "environmental psychology" and "behavior" have the longest span, each of which has more than thirty-six years, indicating that the relationship between environment and behavior is the eternal topic in the domain. In addition, the topic of "climate change" is one of the typical recent research frontiers, which started since 2014 and continued until 2017. The result of clusters analysis shows that "ambient scent", "recycling", "children as outsiders" and "ambient temperature" are the top four largest clusters, which are the popular research topics in the domain of environmental psychology.

Certainly, there are still some limitations in our study. The database employed is only form the Web of Science core collection. In fact, there are many excellent articles about environmental psychology that are not included in this database. Not only need we to expand the scope of the in search, but also, we should further explore the status quo of the environmental psychology research.

\section{Acknowledgement}

This research was supported by the Key Project of Humanities and Social Sciences in Anhui Province of China (Grant NO. SK2015A519 and SK2014A390) and the Revitalization Plans of Anhui Province in China (Grant NO. Szzgih3-20 and Grant NO. Szzjih1-2-2018-19).

15.

\section{References}

1. R. Gifford, ANNU REV PSYCHOL 65,541 (2014)

2. F. H. Rohles, PSYCHOL TDY 1, 54 (1967)

3. A. Gill, B BR PSYCHOL SOC 35, 74 (1982)

4. J. L. Nasar, BEHAV SCI 30, 375 (2015)

5. C. S. Nanninga, L. Meijering, M. C. Schonherr, DISABIL REHABIL 37, 1125 (2015)

6. P. Brown, ENERG RES SOC SCI 31, 215 (2017)

7. Z. M. Moghadam, R. Mirzaei, INT J COMPUT SCI NET SCY 17, 289 (2017)

8. G. Amicone, I. Petruccelli, M. Bonaiuto, PSICO SOC 12, 131 (2017)

9. R. Cervinka, K. Roederer, I. Haemmerle, J ARCHIT PLAN RES 31, 43 (2014)

10. K. Walker-Springett, R. Jefferson, K. Boeck, J ENVIRON MANAGE 166, 525 (2016)

11. J. L. Nasar, J PLAN LIT 30, 375 (2015)

12. J. Song, J. Kim, D. R. Jones, DECIS SUPPORT SYST 59, 37 (2014)

13. C. Chen, J DATA INF SCI 2, 1 (2017)

14. C. Chen, L. Leydesdorff, J ASSOC INF SCI TECH 65, 334 (2014). 